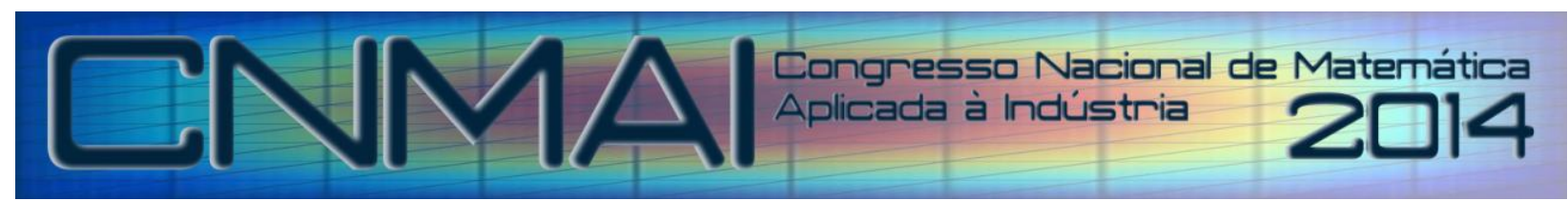

18 a 21 de novembro de 2014, Caldas Novas - Goiás

\title{
PERFORMANCE CRITERIA IN DIFFERENT ASSEMBLY LINE STRUCTURES
}

\author{
Waldemar Grzechca, waldemar.grzechca @polsl.pl \\ The Silesian University of Technology, Institute of Automation Control, Akademicka 16, 44-100 Gliwice, Poland
}

\begin{abstract}
Assembly line balancing problem belongs to the most investigated topics in manufacturing systems. Since 1955 a lot of exact and heuristic methods were developed and implemented to real factories. Another problem, which occurs in balance process, is an estimation of quality measures of final results. Even optimal solution because of precedence relations includes idle times. Therefore despite of methods (exact or heuristics) a good performance criteria allow production engineers or managers to choose the most appropriate solution. The most well-known measures are: line efficiency, smoothness index and time of the line. In literature is possible to find the basic formulae. Unfortunately because of the character of given formulae, it is easy to find ambiguous conclusions about the quality of the results. The reason is a wrong interpretation of cycle time and maximum station load (time). Author presents modified formulae which allow engineers to avoid mistakes in real applications. Additionally, a relation between line structures and their measures of final balance process will be presented. In the second part of paper some numerical experiments will be discussed and the end conclusions and remarks will be given.
\end{abstract}

Keywords: assembly line balancing problem, heuristic methods, heuristic methods, performance criteria

\section{INTRODUCTION}

The manufacturing assembly line was first introduced by Henry Ford in the early 1900's. It was designed to be an efficient, highly productive way of manufacturing a particular product. The basic assembly line consists of a set of workstations arranged in a linear fashion, with each station connected by a material handling device. The basic movement of material through an assembly line begins with a part being fed into the first station at a predetermined feed rate. A station is considered any point on the assembly line in which a task is performed on the part. These tasks can be performed by machinery, robots, and/or human operators. Once the part enters a station, a task is then performed on the part, and the part is fed to the next operation. The time it takes to complete a task at each operation is known as the process time. The cycle time of an assembly line is predetermined by a desired production rate. This production rate is set so that the desired amount of end product is produced within a certain time period (Baybars, 1986). If the sum of the processing times within a station is less than the cycle time, idle time is said to be present at that station (Erel et al., 1998). One of the main issues concerning the development of an assembly line is how to arrange the tasks to be performed. This arrangement may be somewhat subjective, but has to be dictated by implied rules set forth by the production sequence (Kao, 1976). For the manufacturing of any item, there are some sequences of tasks that must be followed. The assembly line balancing problem (ALBP) originated with the invention of the assembly line. Helgeson and Birnie (1961) were the first to propose the ALBP, and Salveson (1955) was the first to publish the problem in its mathematical form. However, during the first forty years of the assembly line's existence, only trial-and-error methods were used to balance the lines (Erel et al., 1998). Since then, there have been numerous methods developed to solve the different forms of the ALBP. Salveson (1955) provided the first mathematical attempt by solving the problem as a linear program. Gutjahr and Nemhauser (1964) showed that the ALBP problem falls into the class of NP-hard combinatorial optimization problems. This means that an optimal solution is not guaranteed for problems of significant size. Therefore, heuristic methods have become the most popular techniques for solving the problem (Fonseca et al., 2005). Even optimal solution because of precedence relations includes idle times. Therefore despite of methods (exact or heuristics) a good performance criteria allow production engineers or managers to choose the most appropriate solution. The most well-known measures are: line efficiency, smoothness index and time of the line. 
In the second section assembly line structures will be presented. In the third section the difference between cycle time and maximum station load will be underlined and explained. A numerical experiment will be described and calculated in section 4. Final conclusions will be given in the section 5 .

\section{ASSEMBLY LINE STRUCTURES AND THEIR PERFORMANCE CRITERIA}

There exists also a classification regarding plant layout which is used to describe the arrangement of physical facilities in a production plant (Scholl, 1998), (Becker and Scholl, 2006), (Rekiek and Delchambre, 2001). Five types of layout can be distinguished:

- serial lines,

- two-sided lines

- U-shaped lines,

- parallel lines,

- parallel stations,

Below serial lines, U-shaped lines and two-sided lines will be considered

\subsection{Serial (Single) Line}

This is a very basic layout of a flow line production system (Fig. 1). It is determined by the flow of materials. It is mostly used for small size products. These lines have several disadvantages:

- monotone work,

- sensibility due to failures,

- inflexibility due to changing demand rates.

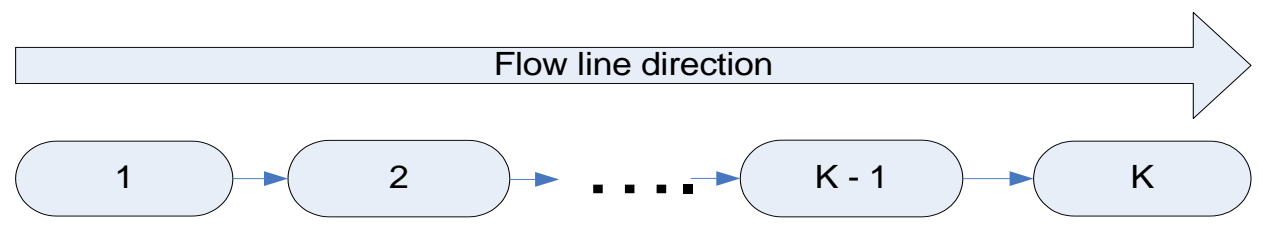

Figure. 1. Serial assembly line structure

Some measures of solution quality have appeared in line balancing problem. Below are presented three of them (Scholl, 1998):

Line efficiency (LE) shows the percentage utilization of the line. It is expressed as ratio of total station time to the cycle time multiplied by the number of workstations:

$$
\mathrm{LE}=\frac{\sum_{\mathrm{i}=1}^{\mathrm{K}} \mathrm{ST}_{\mathrm{i}}}{\mathrm{c} \cdot \mathrm{K}} \cdot 100 \%
$$

where:

$\mathrm{K}$ - total number of workstations,

c - cycle time.

Smoothness index (SI) describes relative smoothness for a given assembly line balance. Perfect balance is indicated by smoothness index 0 . This index is calculated in the following manner:

$$
\mathrm{SI}=\sqrt{\sum_{\mathrm{i}=1}^{\mathrm{K}}\left(\mathrm{ST}_{\max }-\mathrm{ST}_{\mathrm{i}}\right)^{2}}
$$

where:

$\mathrm{ST}_{\max }=$ maximum station time (in most cases cycle time),

$\mathrm{ST}_{\mathrm{i}}=$ station time of station $\mathrm{i}$. 
Time of the line (LT) describes the period of time which is need for the product to be completed on an assembly line:

$$
\mathrm{LT}=\mathrm{c} \cdot(\mathrm{K}-1)+\mathrm{T}_{\mathrm{K}}
$$

where:

c - cycle time,

$\mathrm{K}$ - total number of workstations,

$\mathrm{T}_{\mathrm{K}}$ - time load of the last station in the assembly line.

\subsection{Two-sided Assembly Line}

This kind of flow lines is mainly used in case of heavy work pieces when it is more convenient to operate on both sides of a work piece rather than rotating it. Instead of single working-place, there are pairs of two directly facing stations such as 1 and 2 (Fig. 2). Such a solution makes the line much more flexible as the work piece can be accessed either from left or right. In comparison to serial lines:

- it can shorten the line length,

- reduce unnecessary work reaching to the other side of the work piece.

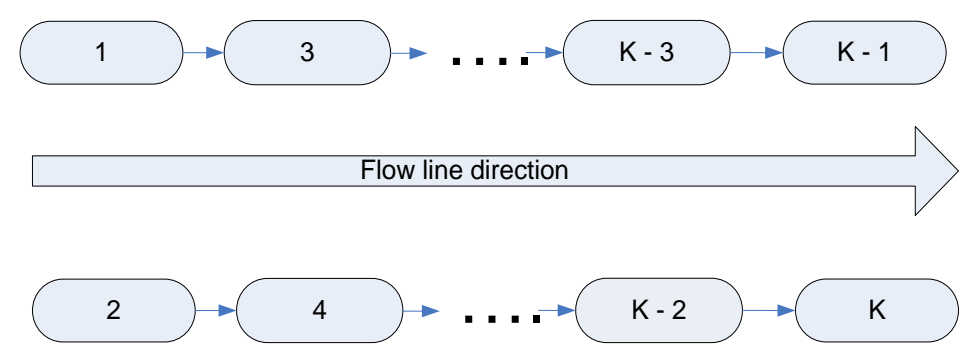

Figure 2. Two - sided assembly line

In two - sided assembly line balancing method within mated-stations, tasks are intended to perform its operations at the same time to the both sides (Bartholdi, 1993), (Kim et al., 2009), (Lee at al., 2001), (Baykasoglu and Dereli, 2008), (Hu et al., 2007). In consequence, modification has to be introduced to line time parameter which is the consequence of parallelism. We must treat those stations as two double ones (mated-stations), rather than individual ones $\mathrm{S}_{\mathrm{k}}$. Accepting this line of reasoning, new formula is presented below:

$$
\mathrm{LT}=\mathrm{c} \cdot(\mathrm{Km}-1)+\operatorname{Max}\left\{\mathrm{t}\left(\mathrm{S}_{\mathrm{K}}\right), \mathrm{t}\left(\mathrm{S}_{\mathrm{K}-1}\right)\right\}
$$

where:

$\mathrm{Km}$ - number of mated-stations,

$\mathrm{K}$ - number of assigned single stations,

$\mathrm{t}\left(\mathrm{S}_{\mathrm{K}}\right)$ - processing time of the last single station.

As far as smoothness index and line efficiency are concerned, its estimation, on contrary to LT, is performed without any change to original version. These criterions simply refer to each individual station, despite of parallel character of the method.

But for more detailed information about the balance of right or left side of the assembly line additional measures will be proposed:

Smoothness index of the left side

$$
\mathrm{SI}_{\mathrm{L}}=\sqrt{\sum_{\mathrm{i}=1}^{\mathrm{K}}\left(\mathrm{ST}_{\operatorname{maxL}}-\mathrm{ST}_{\mathrm{iL}}\right)^{2}}
$$

where:

$\mathrm{SI}_{\mathrm{L}}$ - smoothness index of the left side of two-sided line,

$\mathrm{ST}_{\max }-$ maximum of duration time of left allocated stations,

$\mathrm{ST}_{\mathrm{iL}}$ - duration time of $\mathrm{i}$-th left allocated station. 
Smoothness index of the right side

$$
\mathrm{SI}_{\mathrm{R}}=\sqrt{\sum_{\mathrm{i}=1}^{\mathrm{K}}\left(\mathrm{ST}_{\operatorname{maxR}}-\mathrm{ST}_{\mathrm{iR}}\right)^{2}}
$$

where:

$\mathrm{SI}_{\mathrm{R}^{-}}$smoothness index of the right side of two-sided line,

$\mathrm{ST}_{\max }-$ maximum of duration time of right allocated stations,

$\mathrm{ST}_{\mathrm{iR}}{ }^{-}$duration time of $\mathrm{i}$-th right allocated station.

\subsection{U-shaped Line}

In order to deal with the problems of a serial line it was redesigned to a form of U-shape (Fig. 3). In such a line operators can work at more than one station simultaneously. For example first operator may both load and unload product units. As they are included in more tasks during production process they are gaining very important experience and enlarge horizons. It is very helpful in case of just-in-time production systems as it improves flexibility which is crucial in dynamically changing demand rates. What more, stations are closer together what results in better communication between operators and in case of emergency they are able to help each other effectively (Aase et al., 2004), (Miltenburg, 2001), (Bukchin and Tzur, 2000).

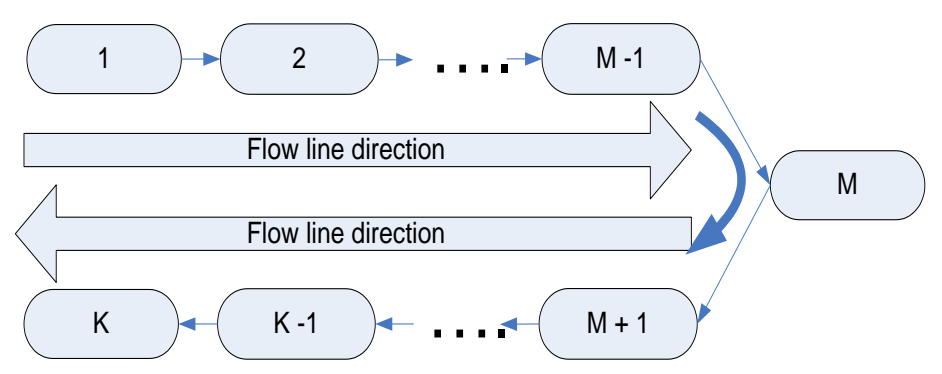

Figure 3. U - Shaped assembly line structure

In this case we should remember that the number of workstation in Eq. (3) is the same as in single line but the last station is different because of the U-shaped structure (input - output).

\subsection{Parallel Lines}

In order to deal with problems described in case of a serial line it might be a good idea to create several lines doing the same or similar tasks (Fig. 4).

The advantages of such a solution (Süer, 1998), (Göcken et al., 2006):

- increased flexibility for mixed-model systems,

- flexibility due to changing demand rates,

- lowered risk of machine breakdown stopping the whole production,

- cycle time can be more flexibly chosen which leads to more feasible solutions.

The optimal number of lines is however a subject of discussion for every single case separately.

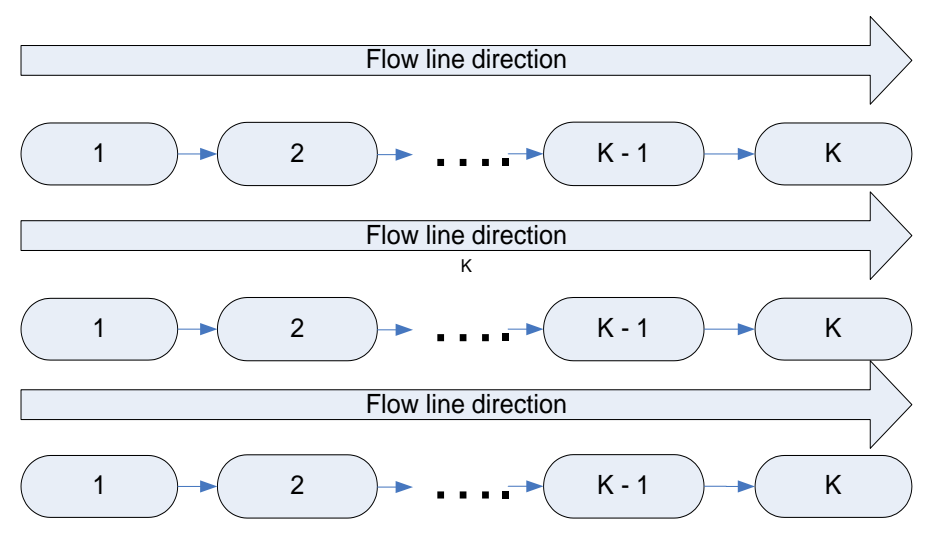

Figure 4. Parallel assembly lines structures 
In this case all measures are the same as in single line stucture. After balancing procedures each line is considered as an independent structure and its performance depends only on the assigning of tasks to the line.

\subsection{Parallel Stations in Straight Line}

As an extension of serial lines bottlenecks are replaced with parallel stations (Fig.5). Tasks performed on parallel stations are the same and throughput is this way increased (Askin and Zhou, 1997), (Bard, 1989), (Pinto et al., 1981), (Bukchin and Rubinovitz, 2003).

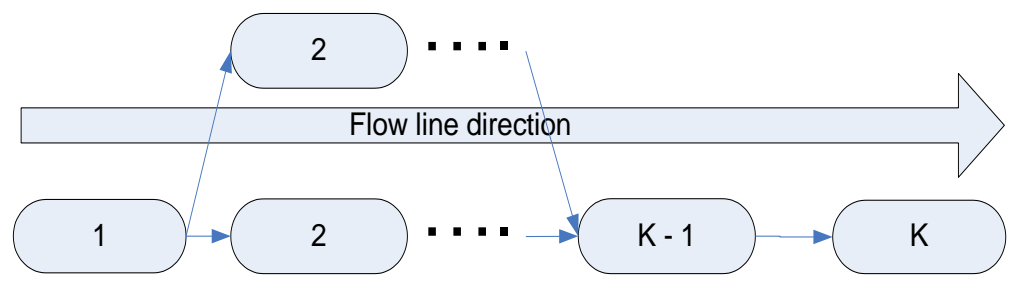

Figure 5. Parallel stations

\section{CYCLE TIME AND MAXIMUM STATION LOAD}

As we can notice there are a lot of wrong calculations and mistakes in final results measures because of Eq.(1) and Eq. (3). The formulae depend on a number of workstations and cycle time. But as we can notice in Eq. (2) cycle time is considered as $\mathrm{ST}_{\max }$ (maximum workstation time). Therefore the formulae should be modified and correct equations are Eq. (7) and Eq. (8). In this way we can avoid mistakes and misunderstanding results.

$$
\mathrm{LE}=\frac{\sum_{\mathrm{i}=1}^{\mathrm{K}} \mathrm{ST}_{\mathrm{i}}}{\mathrm{ST}_{\text {max }} \cdot \mathrm{K}} \cdot 100 \%
$$

and

$$
\mathrm{LT}=\mathrm{ST}_{\max } \cdot(\mathrm{K}-1)+\mathrm{T}_{\mathrm{K}}
$$

The modified equation for line time of two-sided assembly line balancing problem is:

$$
\mathrm{LT}=\mathrm{ST}_{\max } \cdot(\mathrm{Km}-1)+\operatorname{Max}\left\{\mathrm{t}\left(\mathrm{S}_{\mathrm{K}}\right), \mathrm{t}\left(\mathrm{S}_{\mathrm{K}-1}\right)\right\}
$$

\section{NUMERICAL EXAMPLE}

In real systems very often the number of tasks is more than several hundred but for transparency and easy understanding the 30 tasks example will be considered. Below in Fig. 6 a precedence graph is presented and in Tab. 1 operations times are given. All numerical time data are given in time units (tu).

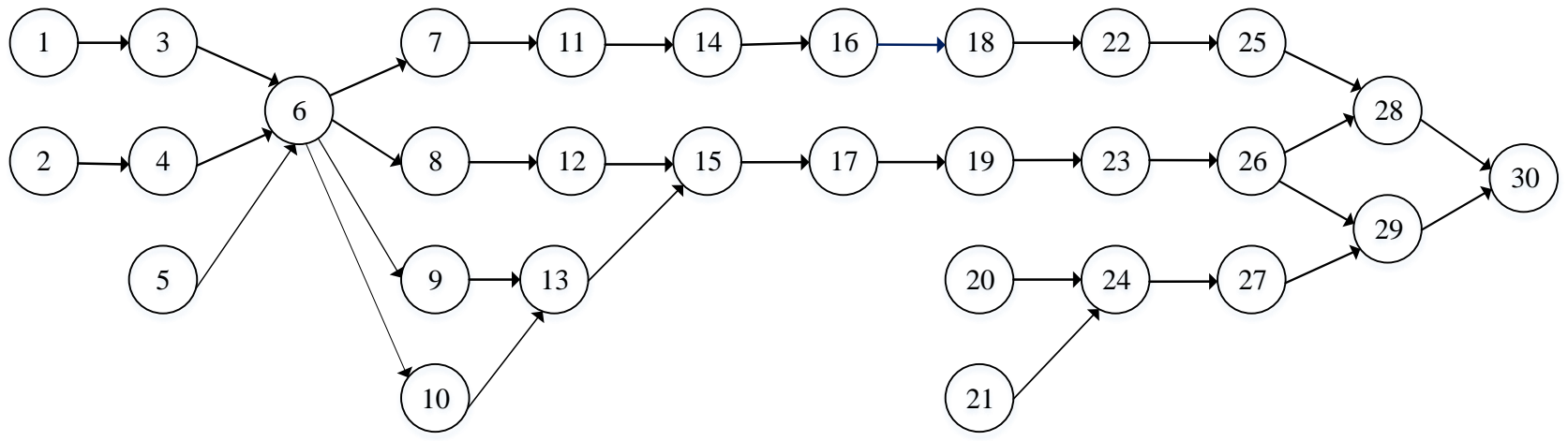

Figure 6. Precedence graph of a numerical example 
Table 1. Operations times of a numerical example

\begin{tabular}{|c|c|c|c|c|c|c|c|c|c|}
\hline Task & $\begin{array}{c}\text { Time } \\
{[\mathrm{tu}]}\end{array}$ & Task & $\begin{array}{c}\text { Time } \\
{[\mathrm{tu}]}\end{array}$ & Task & $\begin{array}{c}\text { Time } \\
{[\mathrm{tu}]}\end{array}$ & Task & $\begin{array}{c}\text { Time } \\
{[\mathrm{tu}]}\end{array}$ & $\begin{array}{c}\text { Task } \\
\text { Time } \\
{[\mathrm{tu}]}\end{array}$ \\
\hline 1 & 3 & 7 & 7 & 13 & 14 & 19 & 4 & 25 & 3 \\
\hline 2 & 4 & 8 & 7 & 14 & 5 & 20 & 5 & 26 & 8 \\
\hline 3 & 6 & 9 & 3 & 15 & 6 & 21 & 7 & 27 & 6 \\
\hline 4 & 1 & 10 & 4 & 16 & 8 & 22 & 3 & 28 & 4 \\
\hline 5 & 3 & 11 & 8 & 17 & 2 & 23 & 7 & 29 & 7 \\
\hline 6 & 6 & 12 & 10 & 18 & 1 & 24 & 4 & 30 & 7 \\
\hline
\end{tabular}

To obtain a balance of assembly line different heuristic methods are presented in the literature (Ranked Positional Weight method, Immediate Update First Fit methods which consider operations processing times, precedence graph with number of followers or predecessors, Hofmann Matrix method, Kilbridge \& Wester's method, etc.) (Gosh and Gagnon, 1989). In this section the RPW method is considered. The ranked positional method was developed by Halgeson and Birnie (1961). This method assigns those jobs first whose followers have the largest total time. The positional weight of work element is its own processing time plus the processing time of all the following work elements. In RPW as stated earlier, the work element with the highest positional weight is selected and assigned to the current workstation. The balance for cycle time $c=17$ and $c=18$ is shown in Fig. 7 and Fig. 8 .

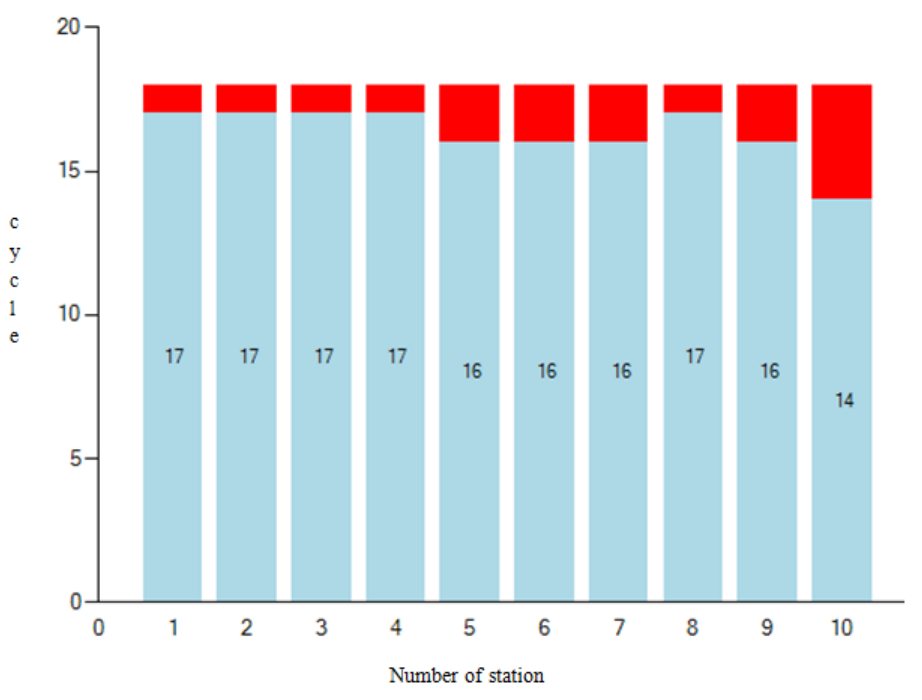

Figure 7. Assembly line balance of the 30-tasks example for cycle $c=18$

The detailed assigning of tasks to the assembly line is presented in Tab. 2.

Table 2. Detailed assigning of tasks to 10 workstations for cycle $\mathrm{c}=18$

\begin{tabular}{|c|c|c|c|}
\hline Workstation & Tasks & Workstation & Tasks \\
\hline 1 & $1-3-2-5-4$ & 6 & $19-23-14$ \\
\hline 2 & $6-10-8$ & 7 & $21-20-24$ \\
\hline 3 & $9-13$ & 8 & $16-26-18$ \\
\hline 4 & $12-7$ & 9 & $27-22-25-28$ \\
\hline 5 & $15-11-17$ & 10 & $29-30$ \\
\hline
\end{tabular}

As we can observe an assembly line with 10 workstations is balanced for cycle time $c=18$. In this case we never obtain a workstation with $100 \%$ of efficiency and each of the workstations includes idle time. If we use to calculate the performance of this balance Eq. (1) $\div$ Eq. (3) we get the following results:

$\mathrm{LE}=90,56 \%$

$\mathrm{LT}=176$ 
Unfortunately, this performance is wrong because of confusing cycle time and maximum load station time. The correct performance for this case should be:

$$
\begin{array}{lll}
\mathrm{LE}=90,56 \% & \mathrm{LT}=176 & \mathrm{SI}=4,9
\end{array}
$$

or

$$
\begin{array}{lll}
\mathrm{LE}=95,89 \% & \mathrm{LT}=167 & \mathrm{SI}=3,61
\end{array}
$$

Both performances are now correct because of considering only cycle time or only maximum load station time. If we decide to change the value of cycle time from $c=18$ to $c=17$ our assignment of tasks don't change but the efficiency of the line increases from $90,56 \%$ to $95,89 \%$. In point of view of managers this right step in increasing production rate of final products. In point of view of production engineers this decision can cause more assembly line stops because of lack the time to correct any mistakes during production process.

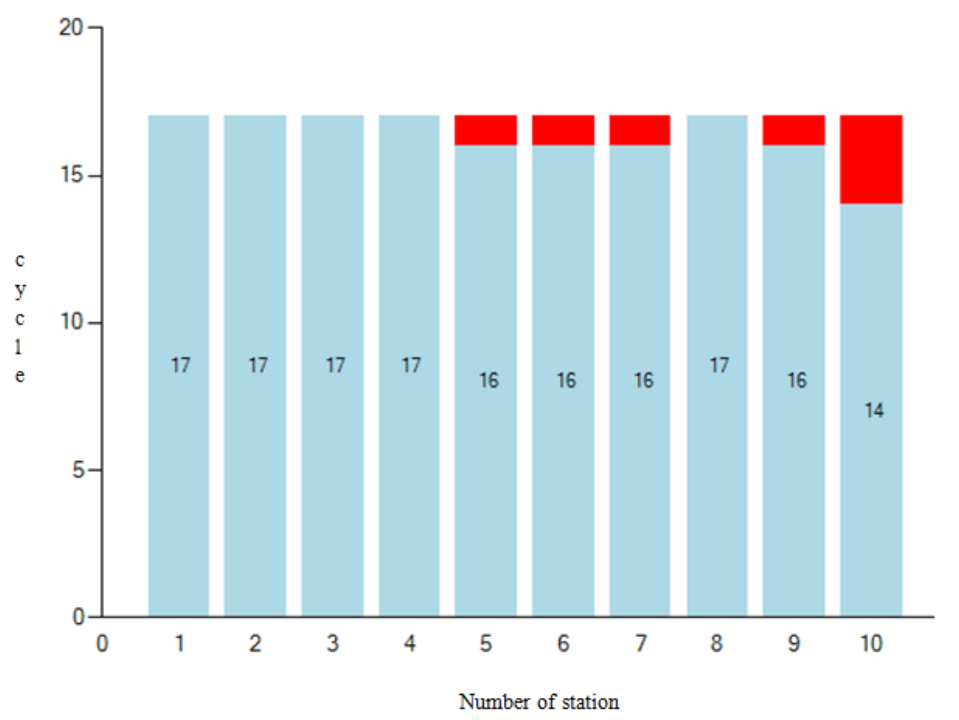

Figure 8. Assembly line balance of the 30-tasks example for cycle $\mathrm{c}=17$

\section{CONCLUSION}

Assembly systems which include assembly lines are one of the most important structures in manufacturing world. We can have different layouts and each of them needs a detailed description. In this article the author wants to underline how important is it to find a correct performance of the assembly line balancing problem. We need to remember that a detailed knowledge allows the managers and production engineers to make appropriate decisions during controlling the production process. Very often the value of line efficiency is not enough to estimate the quality of the balance procedures. The reason is that for the same value of cycle time and the same value of number of workstations the value line efficiency is still the same. It provides the decision makers about the utilization of the assembly structure but lack of detailed knowledge doesn't allow us to solve the problem and improve the system efficiency. As it was shown above in case of confusing cycle time and maximum station load time some mistakes can occur in estimation of final assembly line balancing problem. It is important to remember that cycle time and maximum station load time sometimes differ from each other. To the production engineers belong the decision about changes of cycle time in the system and they should correctly estimate the quality of line efficiency, smoothness index, time of the line or other measures which are known from the literature.

\section{ACKNOWLEDGEMENTS}

This paper was written thanks to support of BK/214/Rau1/2013 grant.

\section{REFERENCES}

Aase, G.R. Olson, J.R. and Schiedierjans, M.J. 2004. U-shaped assembly line layout and their impact on labor productivity: An experimental study. European Journal of Operational Research, vol. 153, No. 3, 698-711

Askin, R.G. and Zhou, M. 1997. A parallel station heuristic for the mixed-model production line balancing problem. International Journal of Production Research, vol. 35, No. 11, 3095-3105 
Bard, J.R. 1989. Assembly line balancing with parallel workstations and dead time. International Journal of Production Research, vol. 27, No. 6, 1005-1018

Bartholdi, J.J. 1993. Balancing two-sided assembly lines: a case study. International Journal of Production Research, vol. 31, No. 10, 2447-2461

Baybars, I. 1986. A survey of exact algorithms for simple assembly line balancing problem. Management Science, vol. 32, No. 8, 909-932

Baykasoglu, A. and Dereli, T. 2008. Two-sided assembly line balancing using an ant-colony based heuristic. International Journal of Advanced Manufacturing Technology, vol. 36, No. 5-6, 582-588

Becker, Ch. And Scholl, A. 2006. A survey on problems and methods in generalized assembly line balancing European Journal of Operational Research, vol. 168, 694-715

Bukchin, J. and Tzur, M. 2000. Designing of flexible assembly lin eto minimize equpment cost. IIE Transactions, 32 , 585-598

Bukchin, J. and Rubinovitz, J. 2003. A weighted approach for assembly line design with station paralleling and equipment selection. IIE Transactions, 35, 73-85

Erel, E. and Sarin, S.C. 1998. A survey of the assembly line balancing procedures. Production Planning and Control, vol. 9, No. 5, 414-434

Fonseca, D.J. Guest, C.L. Elam, M. and Karr C.L. 2005. A Fuzzy Logic Approach to Assembly Line Balancing. Mathware \& Soft Computing, vol. 12, 57-74

Ghosh, S. and Gagnon R.J. 1989. A comprehensive literature review and analysis of the design, balancing and scheduling of assembly lines. International Journal of Production Research, vol. 27, No. 4, 637-670

Gökçen, H. Ağpak, K. and Benzer, R. 2006. Balancing of assembly parallel lines. International Journal of Production Economic, vol. 103, No. 2, 600-609

Gutjahr, A.L. and Neumhauser, G.L. 1964. An algorithm for the line balancing problem. Management Science, vol. 11, No. 2, 308-315

Halgeson, W.B. and Birnie, D.P. 1961. Assembly line balancing using the ranked positional weighting technique. Journal of Industrial Engineering, vol. 12 No. 6, 394-398

$\mathrm{Hu}, \mathrm{X}$. Wu, E. and Jin, Y. 2007. A station oriented enumerative algorithm for two-sided assembly line balancing problem. European Journal of Operational Research, vol. 186, No. 1, 435-440

Kao, E.P.C. 1976. A Preference Order Dynamic Program for Stochastic Assembly Line Balancing. Management Science, vol. 22, No. 10, 1097-1104

Kim, K.Y. Song, W.S. and Kim, J.H. 2009. A mathematical model and a genetic algorithm for two-sided assembly line balancing. Computers and Operations Research, vol. 36, No. 3, 853-865

Lee, T.O Kim, Y. and Kim, Y.K. 2001. Two-sided assembly line balancing to maximize work relatedness and slackness. Computers \& Industrial Engineering, vol. 40, No. 3, 273-292

Miltenburg, J. 2001. U-shaped production lines: A review of theory and practice. International Journal of Production Economics, vol. 70, No. 31, 201-214

Pinto, P. Dannenbring, D.G. and Khumawala, B.M. 1981. Branch and bound heuristic procedures for assembly line balancing with paralleling of stations. International Journal of Production Research, vol. 19, No. 4, 565-576

Rekiek, B. and Delchambre, A. 2001. Assembly line balancing and resource planning: What is done and what is still missing. In: Proceedings of CARS and FOF, Durban, South Africa, 86-93

Salveson, M.E. 1955. The assembly line balancing problem. Journal of Industrial Engineering, vol. 6, No. 3, 18-25

Scholl, A. 1998. Balancing and Sequencing of Assembly Lines, $2^{\text {nd }}$ edition, Physica Verlag Springer Verlag Company, Germany, 1998

Süer, E.A. 1998. Designing parallel assembly lines. Computer and Industrial Engineering, vol. 35, 467-470

\section{RESPONSIBILITY NOTICE}

The author is the only responsible for the printed material included in this paper 